\title{
Technical note: In vitro digestibility of amylase-treated, ash-corrected neutral detergent fiber, with addition of sodium sulfite, at 240 hours with or without rumen fluid reinoculation
}

\author{
A. Palmonari, ${ }^{1}$ G. Canestrari, E. Bonfante, M. Fustini, L. Mammi, and A. Formigoni \\ Department of Veterinary Medicine, Università di Bologna, Bologna, Italy 40064
}

\begin{abstract}
Long-term in vitro fermentation $(240 \mathrm{~h})$ evaluating amylase-treated, ash-corrected neutral detergent fiber, with addition of sodium sulfite (aNDFom) digestibility is required to quantify the indigestible fiber fraction. It is commonly accepted to inoculate rumen fluid more than one time during such fermentations, every $96 \mathrm{~h}$ or at $120 \mathrm{~h}$. However, no studies have been conducted to verify if the reinoculation is actually required to properly carry out the fermentation process. The current study aims to evaluate the effects of these procedures on aNDFom digestibility at $240 \mathrm{~h}$. The study was conducted on a total of 24 forage samples ( 8 alfalfa hays, 8 grass hays, and 8 corn silages). Samples were digested in triplicate at $240 \mathrm{~h}$ in vitro. Rumen fluid was added twice (at 96 and $192 \mathrm{~h}$ ) in treatment 1, after $120 \mathrm{~h}$ in treatment 2 , whereas no addition was made in treatment 3. At the end of the fermentations, residual aNDFom was quantified to calculate digestibility. Among treatments, no difference was found in digestibility of aNDFom. Moreover, treatment 1 resulted in higher variability compared with other treatments. Results obtained in the current study show that subsequent addition of rumen fluid is not necessary for a proper estimation of aNDFom digestibility, and can be avoided.

Key words: in vitro aNDFom digestibility, long-term fermentations, reinoculation process
\end{abstract}

\section{Technical Note}

The in vitro methods requiring rumen inoculum to ferment and digest fibrous material have been used for decades (IVNDFD, Tilley and Terry, 1963; Goering and Van Soest, 1970). The unavailable NDF fraction could be estimated via long-term in vitro fermentations $(240 \mathrm{~h})$, and provides the estimation of the indigestible NDF as related to rumen functions (Palmonari et al., 2016a,b). Unavailable NDF could be also estimated by

Received April 27, 2016.

Accepted October 17, 2016.

${ }^{1}$ Corresponding author: alberto.palmonari2@unibo.it incubating the samples in bags placed in the rumen for $288 \mathrm{~h}$. However, this procedure relies on the availability of cannulated cows and is limited by the intrinsic characteristics of the bags used (Huhtanen et al., 2006; Krizsan and Huhtanen, 2013). On the other hand, the in vitro method is widely applied by commercial and research laboratories. For such procedures, it is usual to add rumen fluid during the fermentation process (Raffrenato, 2011; Palmonari et al., 2014, 2016b). Addition of fresh rumen fluid is usually done every $96 \mathrm{~h}$ or at $120 \mathrm{~h}$. The reason for this addition is to preserve the microbial activity during the assay, because the in vitro method requires substrate as the only limiting factor. Another aspect to consider is related to the laboratory internal error, considered as a source of results variability (Church and Petersen, 1960; Ayres, 1991; Hall and Mertens, 2012). Repeating the addition procedure during the fermentation has to be listed as an error source. Moreover, no studies have been conducted to verify this hypothesis, evaluating if subsequent addition of rumen fluid is necessary to achieve the goal of in vitro fermentations.

In the current study, the effect of 3 different additions of rumen fluid on IVNDFD was tested. In treatment 1 (T96h), rumen content was added to each fermentation vessel every $96 \mathrm{~h}$ ( 2 times total on a 240 $\mathrm{h}$ fermentation), in treatment 2 ( $\mathbf{T} \mathbf{1 2 0 h})$ the addition was provided at $120 \mathrm{~h}$, whereas in treatment 3 (TØ) no rumen fluid was reinoculated during the fermentation process. The study was conducted at the University of Bologna, and all procedures including animals were approved by the University of Bologna Institutional Animal Care and Use Committee. In vitro fermentations were carried out on 24 samples divided in 3 groups based on forage type. The alfalfa hay group (8 different samples) was composed of different cuts (mostly 2nd and 3rd), grass hay (8 unique samples) was mainly composed of different cool-season grasses. Briefly, this pool of grass hay included wheat (Triticum aestivum), Italian ryegrass (Lolium multiflorum), and wild oats (Avena fatua). The corn silage group (8 samples) was representative of some of the main hybrids commonly used for animal feedstuffs in Italy. Samples were dried 
in a forced-air oven $\left(55^{\circ} \mathrm{C}\right)$ for $48 \mathrm{~h}$ and ground through a 1-mm screen in a Cyclone Mill (model SM100, Retsch, Hann, Germany). The samples were then analyzed for amylase-treated, ash-corrected neutral detergent fiber, with addition of sodium sulfite (aNDFom; Mertens, 2002).

For the in vitro fermentations, 2 lactating Holstein cows were selected as donors based on similar BW, parity, DIM, milk production, and milk composition (SCC, fat and protein, lactose, and urea). Animals were milked twice a day. Donor cows were fed a hay-based diet, basically containing alfalfa hay ( $42 \%$ aNDFom,), grass hay ( $48 \%$ aNDFom), and corn grain ( $62 \%$ starch). Rumen fluid was sampled via esophageal probe, pouring off the first volume collected to avoid saliva or mucous contamination, and immediately placed in a thermostatic bottle. Sampling was conducted $0300 \mathrm{~h}$ after feeding. Rumen contents were filtered through 4 layers of cheese cloth under constant $\mathrm{O}_{2}$-free $\mathrm{CO}_{2}$. Once filtered, an equal amount of each liquor collected was sampled and equally mixed with the others.

In vitro fermentations for NDF digestibility were performed at $240 \mathrm{~h}$ using the Tilley and Terry modified technique (Tilley and Terry, 1963; Robertson and Van Soest, 1981), and according to the procedure described by Palmonari et al. (2016b). In particular, $0.5 \mathrm{~g}$ of ground sample was weighed into each flask before the addition of $40 \mathrm{~mL}$ of buffer as described by Goering and Van Soest (1970). Then, $10 \mathrm{~mL}$ of rumen fluid was added to each 150-mL Erlenmeyer flask that had been placed in a heated $\left(39.3^{\circ} \mathrm{C}\right)$ water bath under $\mathrm{CO}_{2}$ positive pressure to ensure anaerobiosis. Flasks were designed with a one-way valve on the surface of the screw cap to allow subsequent addition of liquid substrates without permitting any $\mathrm{O}_{2}$ exposure to the anaerobic environment. For T96h the addition of rumen fluid and buffer solution was repeated 2 times during the fermentation, and once for T120h. For each reinoculation process, $10 \mathrm{~mL}$ of rumen fluid was added to the flasks. Each sample was analyzed in duplicate, in 2 different in vitro incubations. For each forage type and treatment, 2 replicates of blank sample were run. Blanks were prepared as described above but without the addition of any sample, and then treated as the other samples. The 2 fermentations started within $10 \mathrm{~d}$ of each other. For all analysis, sample preparation was the same, as were the donor cows and their diet. At the end of the fermentation, the contents of each flask were analyzed to determine the NDF content of the residue and filtered through crucibles ( $40 \mu \mathrm{m}$ porosity) with the addition of microfiber glass filters $(1.5 \mu \mathrm{m}$, Whatman Limited), according to other authors (Uden, 2006; Raffrenato and Van Amburgh, 2011). Residues were then treated following the procedure described by
Goering and Van Soest (1970), after a 3 h drying in a forced-air oven $\left(105^{\circ} \mathrm{C}\right)$ and hot weighed. Ash correction was made after incineration of the residue at $495^{\circ} \mathrm{C}$ for $3 \mathrm{~h}$, followed by a second crucible hot weigh. Digestibility at any given time point was calculated as described in Equation 1:

$$
\begin{gathered}
\text { IVNDFD, \% aNDFom }= \\
{\left[1-\left(\mathrm{aNDFom}_{\mathrm{r}}-\mathrm{aNDFom}_{\mathrm{b}}\right) / \mathrm{aNDFom}_{\mathrm{i}}\right] \times 100,}
\end{gathered}
$$

where $\mathrm{aNDFom}_{\mathrm{r}}$ is the residual aNDFom, $\mathrm{aNDFom}_{\mathrm{b}}$ is the blank correction, and aNDFom ${ }_{\mathrm{i}}$ represents the initial NDF. All the described terms are expressed in grams.

Statistical analysis was conducted via ANOVA using the JMP-12 software (SAS Institute Inc., Cary NC). The statistical models were run separately for forage group. Measures of averaged digestibility data were considered dependent variables and treatment was the fixed variable. This analysis was carried out on the mean, standard deviation, minimum, and maximum values of the digestibility means. Least squared means were compared using the Tukey adjustment, setting significance level at $P<0.05$.

The in vitro estimation of aNDFom digestibility is reported in Table 1. Average values showed no differences among treatments in any forage types. In the alfalfa hay group digestibility was $51.3,50.4$, and $49.7 \%$, SEM $=2.34$, for T96h, T120h, and TØ, respectively. Average aNDFom digestibility in the grass hay group was 65.1, 67.2 , and $67.3 \%$, SEM $=1.89$, for T96h, T120h, and $\mathrm{T} \varnothing$, respectively, and similar results were observed in the corn silage group $(75.7,77.4$, and $76.7 \%$ SEM $=$ 1.75, for T96h, T120h, and T $\varnothing$, respectively). Minimum and maximum values registered were in line with their respective average values, and did not differ among treatments in any forage type. The analysis of standard deviation within the same forage type resulted in no statistical differences between treatments. Variability within alfalfa hay group was $4.50,3.48$, and $3.46 \%$ for T96h, T120h, and TØ, respectively. Similar results were observed in grass hay group (5.69, 4.27, and 3.98\% for T96h, T120h, and TØ, respectively), and corn silage group (3.69, 2.77, and 3.06\% for T96h, T120h, and $\mathrm{T} \varnothing$, respectively). In general, numerically higher variability was observed in T96h compared with other treatments. The reason of this result could be related to an increased procedural error occurring when addition of rumen fluid and buffer solution was required by the treatment. In T96h, this procedure was repeated 2 times, according to the experimental design. Statistical analysis also showed no differences when digestibility ranges were tested within the same forage type. All the 
Table 1. Digestibility of in vitro amylase-treated, ash-corrected neutral detergent fiber, with addition of sodium sulfite, at $240 \mathrm{~h}$ (mean $\pm \mathrm{SD}$, minimum-maximum values) with different reinoculation strategies ${ }^{1}$

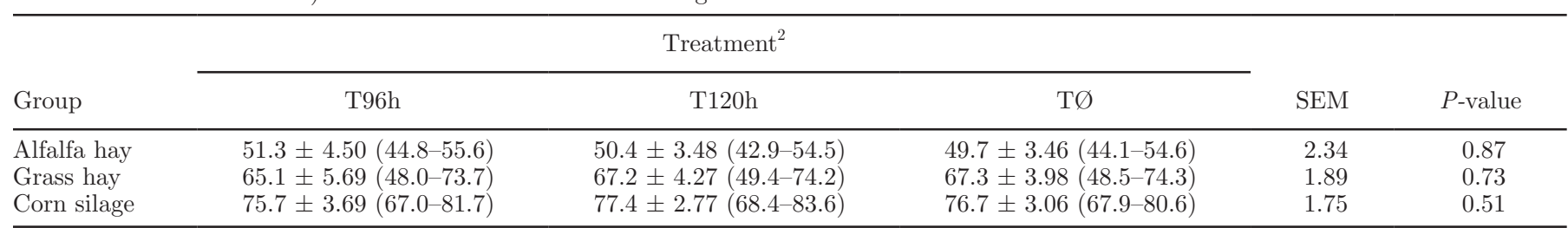

${ }^{1}$ Samples tested were analyzed in 3 groups based on forage type: alfalfa hay $(\mathrm{n}=8)$, grass hay $(\mathrm{n}=8)$, and corn silage $(\mathrm{n}=8)$. Minimum and maximum values are in parentheses.

${ }^{2} \mathrm{~T} 96 \mathrm{~h}=$ addition of rumen fluid every $96 \mathrm{~h}$ during the fermentation process; T120h = addition of rumen fluid at $120 \mathrm{~h}$ during the fermentation process; $\mathrm{T} \varnothing=$ no subsequent addition of rumen fluid during the fermentation process.

treatments showed similar results in their respective minimum and maximum value. This lack of differences could be related to the composition and the complexity of the rumen microbial ecosystem. When testing the effect of rumen fluid source on aNDFom digestibility, Palmonari et al. (2016a) observed similar results among treatments in long-term in vitro fermentations (120 h), despite a source effect occurring at shorter time points (12 and $24 \mathrm{~h}$ ). As suggested by these authors, the in vitro conditions, even if very well standardized and designed to mimic the rumen environment, are indeed substantially different from the rumen itself. Even in the current study, it is possible to hypothesize that some bacterial population are more able than others to adapt to this environment. Moreover, during the fermentation process in which digestible material changes and decreases, a sort of bacterial selection could be listed as a major cause of the similar results obtained among different treatments. Future studies are highly recommended to test this hypothesis, to identify and evaluate these changes on a microbiological perspective. In conclusion, recorded data suggest that reinoculation can be avoided without compromising a proper determination of $240 \mathrm{~h}$ in vitro aNDFom digestibility.

\section{REFERENCES}

Ayres, J. F. 1991. Sources of error with in vitro digestibility assay of pasture feeds. Grass Forage Sci. 46:89-97.

Church, D. C., and R. G. Petersen. 1960. Effect of several variables on in vitro rumen fermentation. J. Dairy Sci. 43:81-92.

Goering, H. K., and P. J. Van Soest. 1970. Forage Fiber Analysis (Apparatus, Reagents, Procedures, and Some Applications). Agricultural Handbook No. 379. USDA Agricultural Research Service, Washington, DC.
Hall, M. B., and D. R. Mertens. 2012. A ring test of in vitro neutral detergent fiber digestibility: Analytical variability and sample ranking. J. Dairy Sci. 95:1992-2003. https://doi.org/10.3168/ jds.2011-4802.

Huhtanen, P., J. Nousiainen, and M. Rinne. 2006. Recent developments in forage evaluation with special reference to practical applications. Agric. Food Sci. 15:293-323.

Krizsan, S. J., and P. Huhtanen. 2013. Effect of diet composition and incubation time on feed indigestible neutral detergent fiber concentration in dairy cows. J. Dairy Sci. 96:1715-1726.

Mertens, D. R. 2002. Gravimetric determination of amylase-treated neutral detergent fiber in feeds with refluxing in beakers or crucibles: Collaborative study. J. AOAC Int. 85:1217-1240.

Palmonari, A., G. Canestrari, M. Fustini, E. Bonfante, L. Mammi, and A. Formigoni. 2016a. Using single or multiple liquor-donor cows for in vitro digestibility of amylase- and sodium sulfite-treated neutral detergent fiber with ash correction. J. Dairy Sci. 99:97549758. https://doi.org/10.3168/jds.2016-11198.

Palmonari, A., M. Fustini, G. Canestrari, E. Grilli, and A. Formigoni. 2014. Influence of maturity on alfalfa hay nutritional fractions and indigestible fiber content. J. Dairy Sci. 97:7729-7734. https://doi. org/10.3168/jds.2014-8123.

Palmonari, A., A. Gallo, M. Fustini, G. Canestrari, F. Masoero, C. J. Sniffen, and A. Formigoni. 2016b. Estimation of the indigestible fiber in different forage types. J. Anim. Sci. 94:248-254. https:// doi.org/10.2527/jas.2015-9649.

Raffrenato, E. 2011. Physical, chemical and kinetics factors associated with fiber digestibility in ruminants and models describing these relations. PhD Diss. Cornell Univ., Ithaca, NY.

Raffrenato, E., and M. E. Van Amburgh. 2011. Technical note: Improved methodology for analyses of acid detergent fiber and acid detergent lignin. J. Dairy Sci. 94:3613-3617.

Robertson, J. B., and P. J. Van Soest. 1981. The detergent system of analysis and its application to human foods. Pages 123-158 in The Analysis of Dietary Fiber in Foods. W. P. T. James and O. Theander, ed. Marcell Dekker, New York, NY.

Tilley, J. M. A., and R. A. Terry. 1963. A two-stage technique for the in vitro digestion of forage crops. J. Br. Grassl. Soc. 18:104-111. https://doi.org/10.1111/j.1365-2494.1963.tb00335.

Uden, P. 2006. Recovery of insoluble fibre fractions by filtration and centrifugation. Anim. Feed Sci. Technol. 129:316-328. https://doi. org/10.1016/j.anifeedsci.2006.01.011. 